\title{
Variation in seed dormancy of the wetland sedge, Carex elongata, between populations and individuals in two consecutive years
}

\author{
Wolfgang Schütz ${ }^{1 *}$ and Gerhard Rave ${ }^{2}$ \\ ${ }^{1}$ Botanisches Institut der Universität Basel, Schönbeinstr. 6, CH-4056 Basel, Switzerland; ${ }^{2}$ Variationsstatistik, \\ Christian-Albrechts-Universität, Olshausenstr. 40, D-24098 Kiel, Germany
}

\begin{abstract}
Variation in dormancy of the wetland sedge, Carex elongata L., was tested using seeds from three wild populations and the garden-grown progeny of one population. Germination experiments, comprising four combinations of temperature and light, were conducted either with fresh-matured or cold-stratified seeds, to assess the relative contribution of populations and mother plants to the total variation. Between-year variation was tested at the population level and, partly, at the individual level, using seeds collected in two consecutive years. Among-population variation accounted for $72 \%$, and among-individual variation for $23 \%$, of the total variance in the first experiment. Significant differences were apparent between one wild population and its garden-grown descendants. Differences in germinability among populations were maintained in the two consecutive years, but a proportion of the variance was due to the contribution of the maternal environment. Weak evidence for genetic control at the individual level was shown by a correlation across years in one population. However, the lack of a main effect at the individual level in the first experiment makes it difficult to assess the relative contribution of the mother plants to the total variation. Our results imply that germination patterns of $C$. elongata have a genetic basis, but are markedly modified by environmental conditions.
\end{abstract}

Keywords: Carex, dormancy variation, genetic control, germination, population

\section{Introduction}

A common characteristic of germination experiments is that $100 \%$ of the viable seeds of a given species

${ }^{*}$ Correspondence:

Fax: +41 (0) 612673504

Email: wschuetz@gmxpro.de rarely germinate. This phenomenon is normally due to variability in dormancy among individual seeds, a trait that probably evolved as a mechanism to reduce the risk of a reproductive failure of seed crops by spreading germination over time (Evans and Cabin, 1995). Sources of variation within a species may occur among populations, among individuals of the same population and within an individual plant. In addition, dormancy levels may vary between years of seed collection. Dormancy studies considering different taxonomic and temporal components in wild plants are scarce, especially studies attempting to quantify the contribution of different levels to the total variation in dormancy (e.g. Acharya et al., 1989; Meyer et al., 1995; Meyer and Allen, 1999).

A problem with many studies is that the germinability of seeds was tested only in a single germination environment, often arbitrarily chosen, or in some cases regarded as optimal for germination. This approach neglects the possible variability in a population, or in an individual, due to different germination environments. Furthermore, there is always the danger that differences between nondormant and conditionally dormant seed batches cannot be detected under optimal conditions, since optimal temperatures for germination tend to diminish differences between populations and individuals (Schütz and Milberg, 1997).

Our study addresses the following questions: (1) Which levels contribute to the variability in seed dormancy of a given species, and how important is their contribution to the total variation? (2) Is there a significant impact of environmental conditions on dormancy of seeds between a wild population and its garden-grown progeny? (3) Is there a difference in dormancy level between years? (4) How large is the impact of experimental conditions on variation of germination data?

We attempted to minimize the possible effects of the maternal environment due to different timing of 
seed ripening, or to differences in seed morphology. Therefore, we chose a species (Carex elongata) in which the onset of anthesis, seed ripening and subsequent shedding occurs almost simultaneously within individual plants, and within populations growing under the same conditions (Schütz, 1997a; personal observation). Hence, differences in dormancy levels due to seed maturation at different times of the year may be regarded as negligible. There are no morphologically distinct structures within the inflorescences and no recognizable size or positional hierarchies within individual plants. Additionally, an attempt was made to reduce site-to-site variation due to climatic and soil conditions to a minimum. Hence, seeds were collected from populations growing under similar conditions at sites situated in a climatically and topographically homogeneous landscape.

Germination of fresh or cold-stratified seeds was tested at four combinations of temperature and light, conditions regarded as suboptimal for germination of C. elongata seeds from preliminary studies (Schütz, 1997a, b, 1999; Schütz and Rave, 1999).

\section{Methods}

\section{Study species}

Carex elongata L. is presumably a long-lived herbaceous perennial with very short rhizomes and densely tufted shoots (Hegi, 1980). This species is closely associated with wet and moderately nutrientrich alder-carrs in northern and central Europe (Bodeux, 1955; Jankovska and Rybnicek, 1988), frequently dominating the herb layer.

Fruit production in C. elongata is normally high, with little variation among years. Empty perigynia, as well as mouldy seeds, are rare and generally do not exceed $1 \%$ of the total number of seeds (Schütz, 1997b; personal observation). On average, a fruit weighs $0.7 \mathrm{mg}$ with the perigynium and $0.53 \mathrm{mg}$ without it. The fruits, which consist of a nutlet and the perigynium, are hereafter referred to as 'seeds'. The germination ecology of $C$. elongata has been studied in detail by Schütz (1997a, b, 1999) and Schütz and Rave (1999). Seeds are conditionally dormant at maturity, and undergo annual non-dormancy/conditional dormancy cycles when buried outdoors. Seedlings emerge in mid-spring in their natural habitat, when mean temperatures are close to $10^{\circ} \mathrm{C}$, and the leaf canopy of the wet deciduous forests has yet to close. The low red/far-red ratio under a closed forest canopy prevents germination of seeds located at the soil surface, leading to seed carry-over to the following years and the incorporation of a sizeable fraction into a seed bank. The seed rain starts immediately after fruit maturation, occurring between the middle and end of June in northern Germany. The seed dispersal period lasts less than about 1 week and has usually ended by early July.

\section{Collection and storage}

Seeds from four populations were collected in 1995 and 1996, shortly before shedding. The collection sites of the three wild populations (B, Belau; P, Pohnsdorf; $\mathrm{H}$, Havighorst) were wet, seasonally inundated aldercarrs on moderately rich organic soils (Schrautzer et al., 1991), situated in depressions of a moraine landscape near Kiel $\left(54^{\circ} 22^{\prime} \mathrm{N} 10^{\circ} 10^{\prime} \mathrm{E}\right)$ in the eastern part of Schleswig-Holstein, northern Germany, between 18 and $50 \mathrm{~m}$ above sea level. The sites are $c$. $15 \mathrm{~km}$ apart. At each site, seeds were collected from at least 30 individual plants. Plants of an additional population $(\mathrm{G})$ were descendants from the C. elongata population of site $\mathrm{B}$ and were grown in an experimental garden. In the alder-carr sites, seeds were sampled at the end of June 1995 and beginning of July 1996 from plants growing under closed canopies, to minimize the effect of varying red/farred light ratios on dormancy (Pons, 2000). Considerable effort was made to harvest all seeds at the final stage of ripening by visiting sites each day after the perigynia had turned to a completely brown colour.

In order to test the variability in dormancy at the individual level, the seeds from six individual plants of each population were harvested separately in 1995. A harvest of individual plants was also planned for 1996, but the setting of seed of the tagged individuals was too low at sites $B, H$ and $G$ to repeat the experiments. Individual differences in dormancy of population $\mathrm{P}$ could be tested only prior to stratification, due to a lack of seeds.

The collected seed batches were air-dried for 3-4 d, whereupon they were cleaned and stored in paper bags in the laboratory at approximately $20^{\circ} \mathrm{C}$ until use. Experiments with fresh seeds started 5-9 d after collection. For stratification, batches of seeds were placed in plastic vessels on a double layer of filter paper moistened with de-ionized water, and kept in a refrigerator at $c .4^{\circ} \mathrm{C}$ for 6 months in darkness.

\section{Garden culture}

Seeds derived from plants of population B were germinated in spring 1992 and cultivated until summer in small plastic pots (9-cm diameter) filled with peat soil. The pots were placed in a tray outdoors in an experimental garden and watered regularly. Six juvenile plants were planted in August in each of four pots of $90-\mathrm{cm}$ diameter and $60-\mathrm{cm}$ height, filled with soil up to $15 \mathrm{~cm}$ below the rim. The soil used for the experiment was collected at the edge 
of a wet alder forest near Kiel. By 1995, the juvenile plants had developed into adult even-sized tussocks, producing abundant seed.

To mimic a flooding regime similar to that of a wet alder-carr, water level in the pots was regulated by holes that were drilled in the walls of the pots at soilsurface level. From the beginning of December to the end of March, the holes were sealed with rubber stoppers, which led to constant flooding due to abundant rainfall. The water level during the rest of the year was maintained between 0 and $5 \mathrm{~cm}$ by adding water to the pots. The pots were placed in an open site, only slightly shaded by a nearby hedgerow during the afternoon. Seeds of the garden population ripened approximately 1 week earlier than those from the alder-carr populations.

\section{Test conditions}

Seeds were tested under four environmental conditions (treatments): fresh seeds at $25^{\circ} \mathrm{C}$ constant temperature in light; fresh seeds at $22 / 10^{\circ} \mathrm{C}$ in light; stratified seeds at $10^{\circ} \mathrm{C}$ constant temperature in light; and stratified seeds at $22 / 10^{\circ} \mathrm{C}$ in darkness. Results of previous germination experiments indicated that these experimental conditions were most likely to result in considerable variation in germination response in $C$. elongata seed populations (Schütz, 1997a, b). Further, they represent temperature and light conditions that approximate to those experienced in the natural environment of this species in various seasons.

Germination tests were carried out in incubators (Rubarth Apparatebau, Hannover, Germany) equipped with warm, white fluorescent light (Philips TL $20 \mathrm{~W} / 29 \mathrm{RS}$ ) providing a photon flux density (PFD) of $20-30 \mu \mathrm{mol} \mathrm{m}^{-2} \mathrm{~s}^{-1}$ at seed level. Twelve hours of light per day were given in all experiments. The maximum temperature period in the $22 / 10^{\circ} \mathrm{C}$ temperature regime was kept constant for $8 \mathrm{~h}$ each day, and the minimum temperature for $12 \mathrm{~h}$. Heating and cooling periods lasted $2 \mathrm{~h}$ each, resulting in a mean temperature of $15^{\circ} \mathrm{C}$. Seeds were placed in 12$\mathrm{cm}$ diameter Petri dishes on filter paper (Schleicher and Schüll, no. 595) and moistened with distilled water. Three replicates of 50 seeds were used for each treatment. Seeds to be incubated in darkness were wrapped in a double layer of aluminium foil under dim green light (Philips TLD $18 \mathrm{~W} / 17$ ) covered with 'medium blue' and 'yellow' filters (LEE Filters, Andover, UK).

Germinated seeds were counted every day or every other day. Counts in the dark treatments were made weekly under dim green light. Since control seeds incubated in darkness at $25^{\circ} \mathrm{C}$ and $22 / 10^{\circ} \mathrm{C}$ did not germinate after exposure to laboratory light for $1 \mathrm{~h}$, it was considered unlikely that the short exposure to green light would promote germination.
Seeds were scored as germinated if the radicle and at least $1 \mathrm{~mm}$ of the green coleoptile were visible. In the calculation of germination percentages, apparently dead seeds, which could be identified based on their softness and brownish colour and generally did not exceed $2 \%$ of the batch, were excluded. Tests were terminated after 7 weeks. To test for germinability, ungerminated but apparently viable seeds were incubated in light at $25^{\circ} \mathrm{C}$. Non-stratified seeds, i.e. those that had been tested shortly after harvesting, were exposed to short cold stratification periods of $2-3$ weeks at $c .5^{\circ} \mathrm{C}$ prior to incubation. Of the remaining seeds, $90-100 \%$ consistently germinated after such a treatment.

\section{Data analysis}

The degree of variation in dormancy due to the sources 'among populations', 'among individuals' and 'within individuals' (i.e. individual mother plants) was estimated using the mixed model analysis available in procedure 'Mixed' of SAS (Littell et al., 1996). A three-level hierarchical design was used to estimate the variance components due to variation in germination (response variable) at the different levels: populations, individuals nested in populations and residual error terms describing the variability within an individual plant. Thus total variance in germination was split into three variance components:

$$
\sigma_{\text {total }}^{2}=\sigma_{\text {population }}^{2}+\sigma_{\text {individual }}^{2}+\sigma_{\text {residual }}^{2}
$$

The treatments, four combinations of light and temperature, were included in the mixed model as fixed factors, to enable computation of interactions: treatments by the random factor 'populations' and treatments by the random factor 'individuals within population'. With these computations, variance components for populations and individuals could be further divided into two components, variance due to main effects and variance due to interaction with treatments:

$$
\begin{aligned}
& \delta_{\text {populaton }}^{2}=\delta_{\text {pop.main }}^{2}+\delta_{\text {pop.interaction }}^{2} \text { and } \\
& \delta_{\text {individual }}^{2}=\delta_{\text {ind.main }}^{2}+\sigma_{\text {ind.interaction }}^{2}
\end{aligned}
$$

The component for main effects estimates the variance due to populations, or individuals within a specific environment, i.e. one of the four treatments. The interaction component estimates gain of variance due to populations or individuals if environment is varied by treatments.

In addition, germination data of the wild population B and its descendents grown in an experimental garden (population G) were compared separately. In this analysis, populations were treated 
as fixed factors and individuals as random factors. The analysis was performed on germination data obtained with seeds harvested in 1995.

The degree of variation across the years, 1995 and 1996, could only be analysed on the population level, because, as mentioned earlier, the setting of tagged individuals was too low in 1996. A two-level hierarchical design was used to estimate the variance components for populations and residual error terms, now describing variability between and within individual plants. With the inclusion of treatments and years as fixed factors, the variance component due to populations was further divided into four components: variance due to main effects, interaction with years, interaction with treatments and the threeway interaction, population by years by treatment.

Differences in germinability among individuals and correlations across years were tested in fresh seeds of population P harvested in 1995 and 1996, using a two-factorial ANOVA.

Germination percentages were arcsinetransformed prior to all analyses to achieve approximately normally distributed data.

\section{Results}

\section{Variation at the individual and at the population level}

Fresh seeds of all C. elongata populations germinated to the highest percentages at $25^{\circ} \mathrm{C}$, whereas only two populations germinated, to some extent, at $22 / 10^{\circ} \mathrm{C}$ in light (Fig. 1). Populations $\mathrm{H}$ and $\mathrm{B}$ were the least dormant, both before and after stratification.

Germinability was significantly different within all three levels. Most of the variation is collected by the factor 'population', since the variance explained by the 'population' component was approximately three times that of the variance caused by individual differences in germinability, which explained $23 \%$ of total variance. Interaction effects due to the different responses of populations to the four treatments were relatively small compared to the main effect, indicating constant (genotypic) differences in dormancy among the populations under the different treatments. By contrast, variability at the individual level was due only to differential responses to the four treatment 'environments', since the main effect of the individual-component did not contribute to the variation. The residual, which represents the withinindividual variation, accounted for only a small amount of total variance (Table 1).

The analysis performed with the germination data from the three 'wild' populations alone (populations $\mathrm{H}, \mathrm{P}$ and $\mathrm{B}$, population $\mathrm{G}$ omitted) (data not shown) yielded similar results, i.e. there was very little change in the relative contribution of the three levels
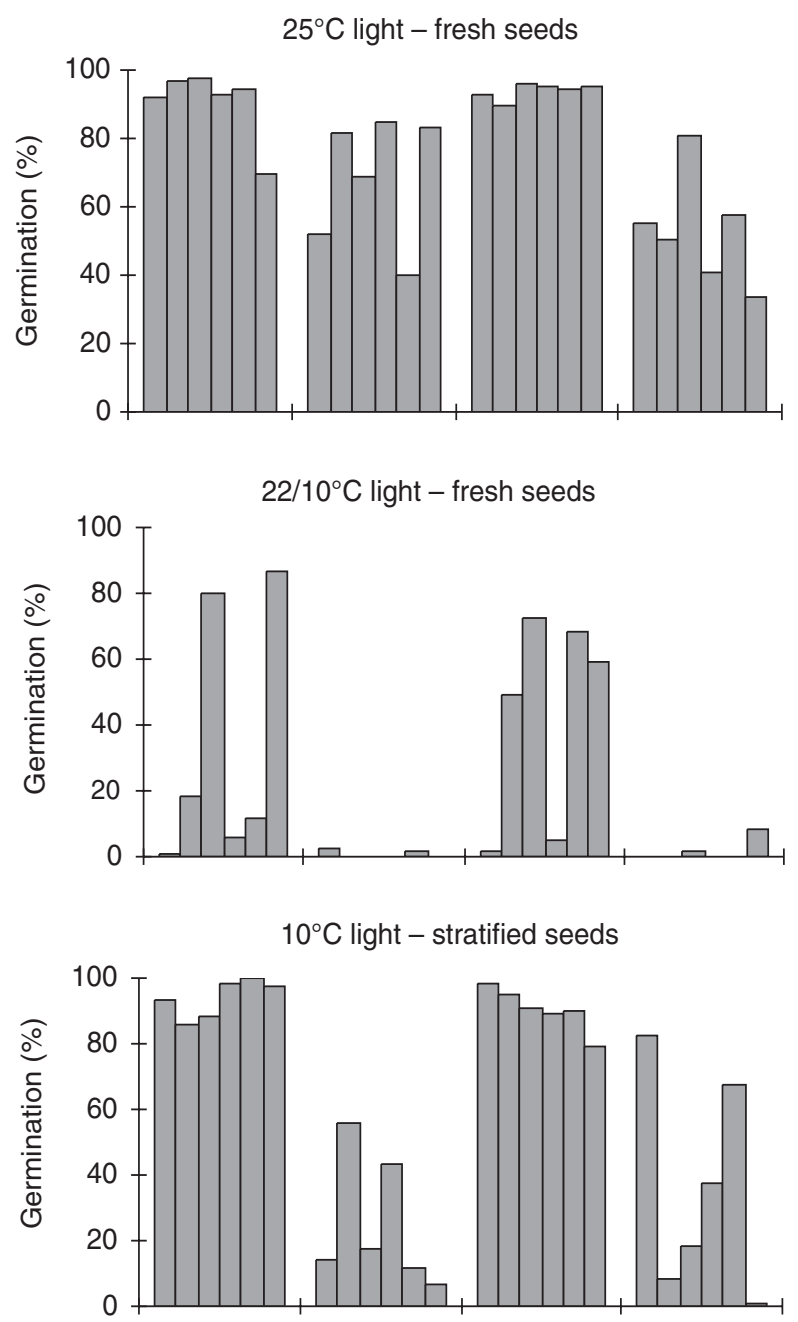

$22 / 10^{\circ} \mathrm{C}$ darkness - stratified seeds

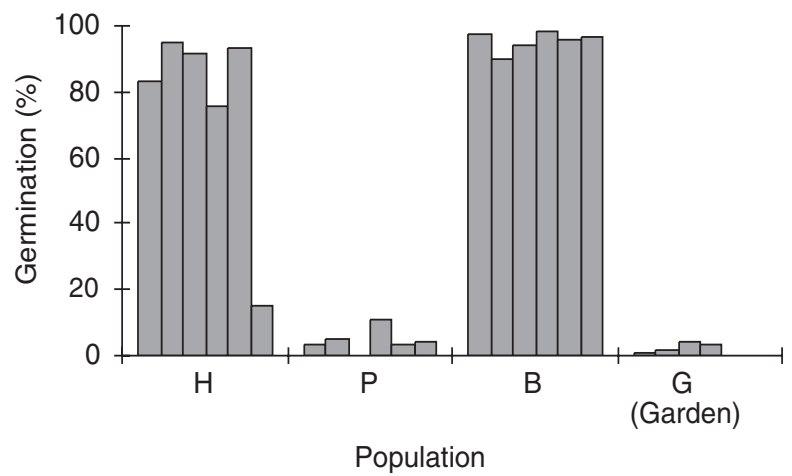

Figure 1. Variation in germinability of Carex elongata among four populations and six individual plants from each population tested with four treatments. Each of the six bars represents an individual plant. Individuals are arranged in the same order in each block. Seeds were harvested in 1995. 
Table 1. Estimation of variance components using germination data (arcsine-transformed) of four populations and six individuals in each population of Carex elongata tested with four treatments. Seeds were harvested in 1995. SE denotes standard error of estimate

\begin{tabular}{lccc}
\hline & \multicolumn{2}{c}{ Variance component } & \\
\cline { 2 - 3 } Source & Estimate & SE & \% of total variance \\
\hline Population & 0.181 & 0.078 & 72.4 \\
Main effect & 0.152 & 0.132 & 60.7 \\
Interaction treatment & 0.029 & 0.019 & 11.7 \\
Individuals & 0.058 & 0.010 & 23.3 \\
Main effect & $0^{\mathrm{a}}$ & - & 0 \\
Interaction treatment & 0.058 & 0.010 & 23.3 \\
Residual & 0.011 & 0.001 & 4.8 \\
\hline
\end{tabular}

a The estimated variance component was negative and thus set to zero.

to the total variation. However, estimates are less reliable simply due to the fact that only three populations were included in the analysis.

Population B and its descendants grown in the experimental garden $(\mathrm{G})$ differed significantly in their germination response when analysed separately (main effect 'population': $\mathrm{df}=1, F=117.62, P=$ 0.0001).

\section{Variation between years at the population level}

Overall germination across all populations and treatments was $36 \%$ in 1995, and 55\% in 1996. The increase was due to the stronger positive effect of stratification on germination in $1996\left(10^{\circ} \mathrm{C}\right.$ in light and $22 / 10^{\circ} \mathrm{C}$ in darkness), and it was evident in all populations. By contrast, germinability in fresh seeds tested at $25^{\circ} \mathrm{C}$ in light was slightly lower in 1996 than in 1995, and approximately equal in both years at $22 / 10^{\circ} \mathrm{C}$ in light (Fig. 2).

Main effects explained considerably more of the variation than interaction effects (year $\times$ population, and treatment $\times$ population), indicating consistent differences among populations also across years (Table 2). The interaction effect 'year $\times$ population' was about one-fourth of the main effect and can be regarded as an indicator of the influence of the maternal environment during seed ripening. The size of the second-order interaction (year $\times$ population $\times$ germination environment) was unexpectedly high, which indicates that genotypic variance changes between years. However, the considerable size of the standard deviations, relative to the estimates, limits the possibilities of drawing firm conclusions on the nature of these interaction effects.

Exclusion of population G from the analysis (not shown) did not alter the rank order of the contribution of factors and interactions to total variance, although estimates deviated more strongly from those obtained with the data set that included all populations.

\section{Variation between years at the individual level}

Average germination of seeds from the six individual plants of population $\mathrm{P}$ at $25^{\circ} \mathrm{C}$ in light was $70 \%$ in 1995 and 55\% in 1996. Differences among individuals (ANOVA, $\mathrm{df}=5, F=11.3, P=0.0001$ ) and between years $(\mathrm{df}=1, F=7.4, P=0.01)$ were statistically significant at the 5\% level. However, there was no significant interaction effect at the $5 \%$ level $(\mathrm{df}=5, F=$
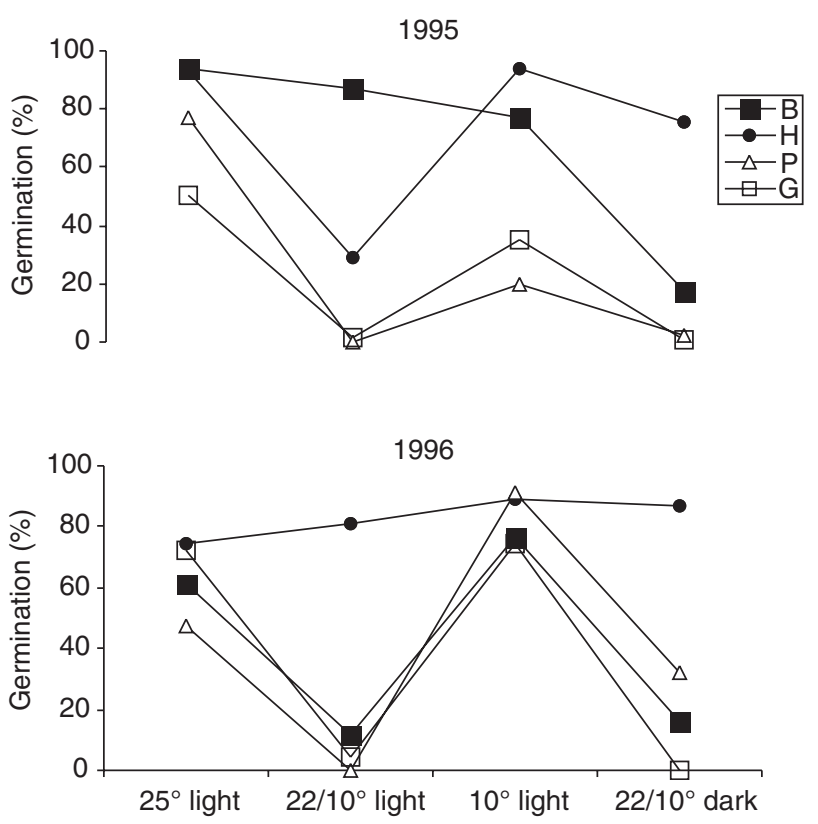

Figure 2. Germination percentages of seeds from four Carex elongata populations collected in two successive years (1995 and 1996) and tested with the four indicated treatments. 
Table 2. Estimation of variance components using germination data (arcsin-transformed) of four populations of Carex elongata, harvested in 2 years (1995 and 1996) and tested under four treatments. SE denotes standard error of estimate

\begin{tabular}{lccc}
\hline & \multicolumn{2}{c}{ Variance component } & \\
\cline { 2 - 3 } Source & Estimate & \% & \% of total variance \\
\hline Populations & 0.115 & 0.035 & 81.6 \\
$\quad$ Main effect & 0.040 & 0.046 & 28.4 \\
Interaction years & 0.008 & 0.010 & 6.0 \\
Interaction treatment & 0.004 & 0.019 & 2.8 \\
Interaction year by treatment & 0.062 & 0.033 & 44.0 \\
Residual & 0.026 & 0.004 & 18.4 \\
\hline
\end{tabular}

2.6, $P=0.06)$, probably because the rank order in germinability of individuals of population $\mathrm{P}$ coincided for 1995 and 1996 (Fig. 3). Average germination of fresh seeds at $22 / 10^{\circ} \mathrm{C}$ in light was $<1 \%$ in 1995 and zero in 1996.

\section{Discussion}

Considerable variation in seed dormancy of $C$. elongata occurred among populations, among individuals and within individuals, but differences among populations contributed most to the total variation. The same rank order was apparent in a study on phenotypic variance in germinability of Bromus tectorum, but differences among populations accounted for a greater proportion (over $90 \%$ ) of the variance, while the smaller proportion $(10 \%)$ could be attributed to among-individual and within-individual variation (Meyer and Allen, 1999). Thus, the results for both species indicate that intraspecific differences in dormancy are predominantly genotypic, and

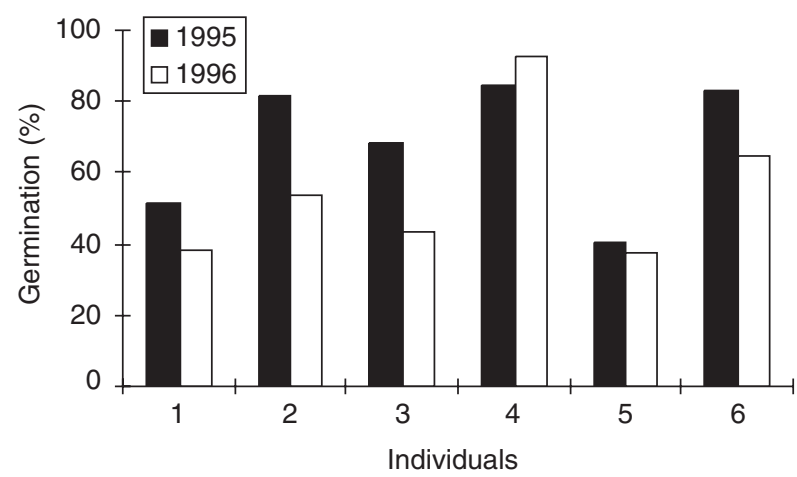

Figure 3. Germination percentages of fresh seeds from six individual plants of a Carex elongata population $(\mathrm{P})$ at $25^{\circ} \mathrm{C}$ constant temperature in light. Seeds were harvested in 1995 and 1996. located mainly at the population level. However, variance estimates for C. elongata contain an unknown component that can be attributed to possible differences in seed ripening conditions at the four collection sites, while the B. tectorum plants were grown under controlled conditions in a greenhouse. Therefore, the potential influence of maternal effects on dormancy might have been stronger in our study than in the study conducted with B. tectorum. In addition, the higher proportion of variance accounted for by populations in $B$. tectorum could be a consequence of the sampling design. B. tectorum populations were collected from sites differing widely in climate, whereas the C. elongata populations were growing under similar climatic and edaphic conditions. Consequently, the between-population differences in the germination response of $B$. tectorum appeared to be related to some character of the habitat (potential risk of precocious summer germination) (Beckstead et al., 1996), while the probability of differences among populations due to genetic adaptation to local conditions may be much smaller in C. elongata.

The results of the first experiment were largely corroborated by the second experiment, although a considerable part of the variance in dormancy could be attributed to between-year differences. However, the significance of our between-year comparison of germinability among populations remains weak, for obvious reasons. Clearly, more than 2 years are needed to detect a consistent relationship between the dormancy levels of populations and annual shifts of climatic conditions during seed ripening. Betweenyear variations in dormancy have been reported at the population level (e.g. Baskin and Baskin, 1975; Acharya et al., 1989; Young et al., 1991; Schmitt et al., 1992; Evans and Cabin, 1995; Meyer et al., 1995; Andersson and Milberg, 1998; Qaderi and Cavers, 2002), but most studies are restricted to a period of 2 years, as in the present study. Estimates of the relative contribution of interannual to total variation in 
dormancy are few. In the germination of Amelanchier alnifolia, only $17.8 \%$ of the total variance could be assigned to year and population-by-year interactions (Acharya et al., 1989).

The importance of the genetic component is less apparent at the level of individuals of C. elongata, although $23 \%$ of the total variance was located at the individual level in the first analysis. Variability at the individual level was apparently due only to differential responses to treatments, indicating a high phenotypic plasticity. On the other hand, lack of a significant individual-by-year interaction in fresh seeds of $C$. elongata from population $P$, an indication of a correlation across years, provides evidence that genetic control of seed dormancy also exists at the individual level. However, the evidence is weak due to the limited extent of this experiment and the fact that the interaction becomes marginally significant when the level of error probability is enhanced to $10 \%$. Evidence for genetic differences in dormancy among individual plants has been detected in other species. For instance, garden experiments with the genus Penstemon showed that germination differences had a strong genetic basis, both among populations and among plants in a population (Meyer et al., 1995). The mean germination response of individual plants of Penstemon palmeri was significantly correlated across years, indicating the contribution of an among-individual genetic component to the variation.

The degree of genetic control of seed dormancy can differ widely between species. A strong genetic basis of seed dormancy has been shown for some species (Jana and Naylor, 1980; Garbutt and Witcombe, 1986; Meyer et al., 1995; Meyer and Allen, 1999), but the opposite is true for others (Baskin and Baskin, 1973; Panetta and Randall, 1993; Andersson and Milberg, 1998). Andersson and Milberg (1998) questioned the overriding importance of genetic control in four annual weeds. They detected large variations in seed dormancy among individuals, among populations and between years. They concluded that the impact of maternal environment accounted for most of the differences in dormancy, and that the investigated species have a random pattern of variation in dormancy level.

Can we establish a similar phenomenon in $C$. elongata? On the one hand, there was no consistent rank order in the germination response of populations to identical treatments in the 2 years of investigation. For instance, imbibition of freshly matured seeds to $22 / 10^{\circ} \mathrm{C}$ in light had opposing effects in populations $\mathrm{B}$ and $\mathrm{P}$ in different years. Moreover, the rank order of individual germination percentages was not the same in the four treatments of the first experiment, indicating a certain degree of unpredictability in germination response. On the other hand, a prevalence of random effects, as claimed by Andersson and Milberg (1998) for all taxonomic levels investigated, is unlikely in $C$. elongata, since differences in dormancy patterns largely corresponded among populations and between years.

Random responses to identical environmental cues may be part of a germination strategy in which high germination plasticity in response to temperature cues enhances the temporal variability of germination. Variation among individuals, in particular, will reduce sib competition and enhance the genetic variation within a population by increasing the age distribution of seeds in the soil seed bank (Bosbach et al. 1982; Andersson and Milberg 1998).

However, significant differences in the degree of seed dormancy between a wild population and its garden-grown progeny may indicate that the magnitude of the genetic component to phenotypic variation depends strongly on the local environmental conditions under which seeds ripened (garden versus alder-carr). The garden-grown population experienced climatic conditions quite different from those of the alder-carrs, i.e. higher temperatures and a higher light level during seed maturation. Major changes in environmental conditions may reveal a higher plasticity in germination responses than could be detected by comparing populations growing under similar conditions in a given habitat.

Our results imply the necessity to test seed germination (or any other single plant trait) under more than one condition if quantitative estimates of the degree of phenotypic plasticity and the proportion of genetic contribution to the variation in germination response are desired. There is always the danger of achieving germination percentages close to 0 or $100 \%$, rendering it impossible to detect differences at any taxonomical level. It is also desirable to test germination when seeds are freshly matured and after pre-treatments (stratification, dry afterripening), which represent habitat conditions between seed ripening and main emergence time, to evaluate their potential to respond differentially to changing environmental conditions (Milberg and Andersson, 1998).

However, it was not possible (1) to detect environmental cues that determined the degree of primary dormancy; and (2) to establish the role of climatic conditions during seed ripening and the extent of their effects on seed dormancy variability in C. elongata on the basis of our two-year study. Furthermore, it remains to be shown if the proportion of variance components at the various taxonomic levels is consistent across years. 


\section{References}

Acharya, S.N., Chu, C.B. and Hermesh, R. (1989) Effects of population, environment and their interaction on Saskatoon Berry (Amelanchier alnifolia Nutt.) seed germination. Canadian Journal of Plant Science 69, 277-284.

Andersson, L. and Milberg, P. (1998) Variation in seed dormancy among mother plants, populations and years of seed collection. Seed Science Research 8, 29-38.

Baskin, J.M. and Baskin, C.C. (1973) Plant population differences in dormancy and germination characteristics of seeds: heredity or environment? American Midland Naturalist 90, 493-498.

Baskin, J.M. and Baskin, C.C. (1975) Year-to-year variation in the germination of freshly-matured seeds of Arenaria patula var. robusta from the same site. Journal of the Tennessee Academy of Science 50, 106-108.

Beckstead, J., Meyer, S.E. and Allen, P.S. (1996) Bromus tectorum seed germination: between-population and between-year variation. Canadian Journal of Botany 74, 875-882.

Bodeux, A. (1955) Alnetum glutinosae. Mitteilungen der Floristisch-soziologischen Arbeitsgemeinschaft 5, 114-157.

Bosbach, K., Hurka, H. and Haase, R. (1982) The soil seed bank of Capsella bursa-pastoris (Cruciferae); its influence on population variability. Flora 172, 47-56.

Evans, A.S. and Cabin, R.J. (1995) Can dormancy affect the evolution of post-germination traits? The case of Lesquerella fendleri. Ecology 76, 344-356.

Garbutt, K. and Witcombe, J.R. (1986) The inheritance of seed dormancy in Sinapis arvensis L. Heredity 56, 25-31.

Hegi, G. (1980) Illustrierte Flora von Mitteleuropa, Vol. 2(1) (3rd edition). Berlin, Parey.

Jana, S. and Naylor, J.M. (1980) Dormancy studies in seed of Avena fatua. 11. Heritability for seed dormancy. Canadian Journal of Botany 58, 91-93.

Jankovska, V. and Rybnicek, K. (1988) The genus Carex in the Late Glacial and Holocene of Czechoslovakia. Aquatic Botany 30, 23-38.

Littell, R.C., Milliken, G.A., Stroup, W.W. and Wolfinger, R.D. (1996) SAS system for mixed models. Cary, NC, SAS Inc.

Meyer, S.E. and Allen, P.S. (1999) Ecological genetics of seed germination regulation in Bromus tectorum L. I. Phenotypic variance among and within populations. Oecologia 120, 27-34.

Meyer, S.E., Kitchen, S.G. and Carlson, S.L. (1995) Seed germination timing patterns in intermountain Penstemon (Scrophulariaceae). American Journal of Botany 82, 377-389.
Milberg, P. and Andersson, L. (1998) Does cold stratification level out differences in seed germinability between populations? Plant Ecology 134, 225-234.

Panetta, F.D. and Randall, R.P. (1993) Variation between Emex australis populations in seed dormancy/nondormancy cycles. Australian Journal of Ecology 18, 275-280.

Pons, T.L. (2000) Seed responses to light. pp. 237-260 in Fenner, M. (Ed.) Seeds - the ecology of regeneration in plant communities (2nd edition). Wallingford, CABI Publishing.

Qaderi, M.M. and Cavers, P.B. (2002) Interpopulation and interyear variation in germination in Scotch thistle, Onopordum acanthium L., grown in a common garden: Genetics vs. environment. Plant Ecology 162, 1-8.

Schmitt, J., Niles, J. and Wulff, R.D. (1992) Norms of reaction of seed traits to maternal environments in Plantago lanceolata. American Naturalist 139, 451-466.

Schrautzer, J., Härdtle, W., Hemprich, G. and Wiebe, C. (1991) Zur Synökologie und Synsystematik gestörter Erlenwälder im Gebiet der Bornhöveder Seenkette (Schleswig-Holstein). Tuexenia 11, 293-307.

Schütz, W. (1997a) Are germination strategies important for the ability of cespitose wetland sedges (Carex) to grow in forests? Canadian Journal of Botany 75, 1692-1699.

Schütz, W. (1997b) Primary dormancy and annual dormancy cycles in seeds of six temperate wetland sedges. Aquatic Botany 59, 75-85.

Schütz, W. (1999) Germination responses of temperate Carex-species to diurnally fluctuating temperatures - a comparative study. Flora 194, 21-32.

Schütz, W. and Milberg, P. (1997) Seed dormancy in Carex canescens - regional differences and ecological consequences. Oikos 78, 420-428.

Schütz, W. and Rave, G. (1999) The effect of cold stratification and light on the seed germination of temperate sedges (Carex) from various habitats and implications for regenerative strategies. Plant Ecology 144, 215-230.

Young, J.A., Palmquist, D.E. and Evans, R.A. (1991) Temperature profiles for germination of big sagebrush seeds from native stands. Journal of Range Management 44, 385-390.
Received 13 January 2003

accepted after revision 2 July 2003

(C) CAB International 2003 